\title{
Effects of stimulus dimension and of trial and intertrial illumination on acquisition of a match/mismatch task by pigeons
}

\author{
CHARLES A. EDWARDS \\ Dalhousie University, Halifax, Nova Scotia, Canada \\ and \\ JAMES S. MILLER, THOMAS R. ZENTALL, and JOYCE A. JAGIELO \\ University of Kentucky, Lexington, Kentucky
}

\begin{abstract}
Birds were trained on a higher order conditional discrimination task, one that required birds to match samples and comparisons on some trials and to mismatch on other trials. Which task component was in effect was indicated by the level of chamber illumination (houselight-on and houselight-off instructions). Acquisition of the components of a color (red and green) match/mismatch task in the first half of the experiment was not differentially affected by the level of illumination associated with each task component, by houselight changes per se, or by the level of illumination during the intertrial interval (ITI). However, when shapes (plus and circle) were used to train the task in the second half of the experiment, performance on the houselight-cued task component exceeded performance on the dark-cued task component, and ITI illumination facilitated performance on both task components. These results suggest that attention to shape stimuli, but not to colors, may vary systematically as a function of chamber illumination level.
\end{abstract}

A common finding in visual discrimination research with pigeons is that discriminations between color stimuli are easier to learn than discriminations between line orientations (Carter \& Eckerman, 1975) or geometric forms (Cumming \& Berryman, 1965; Farthing \& Opuda, 1974). Faster acquisition of tasks that require color discriminations, rather than form discriminations, has been obtained both in simple discrimination tasks (Carter \& Eckerman, 1975) and in complex conditional discrimination tasks, such as matching-to-sample and symbolic matching (Carter \& Werner, 1978). Differences in discriminative performance that can be attributed to stimulus dimension are not confined to task acquisition. Studies of delayed matching-to-sample have consistently found that memory for color samples is better than memory for form samples (e.g., Cook, 1980; Farthing, Wagner, Gilmour, \& Waxman, 1977). Other studies have also shown that when color and form stimuli are combined to produce stimulus compounds, pigeons may selectively attend to the color element of the compound (e.g., Born \& Peterson, 1969; Seraganian, 1979).

The reason for this difference in the discriminability of colors and shapes is not clear. However, we recently reported the results of a study that suggested that the discriminability of forms, but not colors, may vary system-

\footnotetext{
The authors wish to thank Pamela Jackson for her assistance in running subjects and Marcia Spetch for her helpful comments on an earlier version of the manuscript. Requests for reprints may be addressed to the first author, who is now at the Department of Psychology, University of Texas at El Paso, El Paso, TX 79968.
}

atically as a function of the level of chamber illumination (Edwards, Miller, \& Zentall, 1985). Birds were trained on a higher order conditional discrimination task, one that was equivalent to combining a matching-to-sample task with an oddity-from-sample task. Thus, birds were required to match sample and comparison stimuli on some trials and to mismatch the same sample and comparison stimuli on other trials. Across trials, the level of chamber illumination was varied to indicate whether a matching response or a mismatching response would be reinforced (i.e., the houselight was either on or off during a trial and it was off during all intertrial intervals).

The stimuli used to train the task consisted of an illuminated plus and circle, each presented against a dark surround. Circle and plus appeared equally often as samples and comparisons on both the matching and the mismatching components of the task. The birds could not learn the task by learning associations between each sample and one of the comparison stimuli, because for each sample stimulus the value of the correct comparison was reversed across houselight-on and houselight-off conditions. Instead, the birds had to use the houselight as a cue for solving the task.

Our major finding during the birds' acquisition of this shape match/mismatch task was that they learned the houselight-cued task component before learning the darkcued task component. After $\mathbf{4 4}$ sessions of training, the birds averaged $79 \%$ correct on the houselight-cued component of the task, but performance on the dark-cued component averaged only $61 \%$ correct. Because task compo- 
nent (match/mismatch) and houselight levels (on or off) were counterbalanced across two groups during training, the asymmetry in rates of learning the components of the task could not be attributed to differences in the ease of learning matching or mismatching. Rather, faster acquisition of the component cued by the houselight appeared to depend on chamber illumination per se. ${ }^{1}$

The acquisition data indicated that the birds readily discriminated the shape stimuli when the houselight remained on during a trial, but that they had difficulty in discriminating the same stimuli when the houselight was off. Interestingly, when the birds were subsequently shifted to a color (red or green) match/mismatch task, there was no evidence for the kind of asymmetry that was obtained with shapes. Thus, the houselight effect (better performance on the houselight-cued component than on the dark-cued component) appeared to depend on which of the two stimulus dimensions (shape or color) was represented by the sample and comparison stimuli.

The purpose of the present experiment was to further examine the houselight effect, while controlling for several variables that were confounded in the earlier experiment. One confound was that a differential reward manipulation was employed, so that correct responses on the houselight-cued component of the task were reinforced with one kind of grain, whereas correct responses on the dark-cued component were reinforced with a different kind of grain. We attempted to select grains that were equally preferred; however, houselight cues and kind of grain reward were not counterbalanced, and we cannot rule out the possibility that preferences developed with training. One could thus argue that faster acquisition of the houselight-cued task component simply reflected a preference for the reward associated with that task component. In the present study, which provided the opportunity to replicate the earlier shape acquisition data, we eliminated food preference as a factor by providing the same reinforcer for correct responses on both components of the task.

A second confound in the earlier experiment was that changes in houselight-produced illumination accompanied houselight-cued trials (i.e., houselight onset at the beginning and houselight offset at the end of a trial), whereas no change in houselight-produced illumination accompanied dark-cued trials (the houselight remained off before, during, and after such trials). Under these conditions, it was possible that houselight changes per se, and not the absolute level of houselight illumination during a trial, contributed to faster acquisition of the houselight-cued component of the task. Additional groups were included in the present experiment to control for changes in houselight-produced illumination at the start of a trial.

A third problem was that the order in which the shape and color tasks were trained was not counterbalanced. It is possible that illumination per se had a differential effect when birds were trained with shapes because this was the birds' first exposure to the match/mismatch task. Additional training may have reduced the houselight effect so that by the time birds were given the color problem, no asymmetry was observed. To rule out this possibility, we reversed the order in which the problems were trained (color training followed by shape training) in the present experiment.

\section{METHOD}

\section{Subjects}

Sixteen experimentally naive loft-reared pigeons, of mixed age and sex, were obtained from a local breeder. The birds were food deprived and were maintained at $80 \%-85 \%$ of their free-feeding weights. They were individually housed in wire-mesh cages, and free access to water and grit was provided.

\section{Apparatus}

The apparatus (the same as that used in the earlier match/mismatch study; see Edwands et al., 1985) was a standard operant chamber that measured $30 \mathrm{~cm}$ wide, $35 \mathrm{~cm}$ high, and $35 \mathrm{~cm}$ across the stimulus panel. The stimulus panel contained three horizontally aligned rectangular response keys. Each key measured $3.2 \mathrm{~cm}$ wide $\times 2.5 \mathrm{~cm}$ high, and the bottom edges of the keys were $16.0 \mathrm{~cm}$ above a wire-mesh floor. IEE in-line projectors located behind each response key were used to illuminate the keys with red or green hues (Kodak Wratten filters No. 26 and No. 60, respectively), or one of two white shapes (plus or circle) on a black background. The plus consisted of a horizontal and vertical line, each $18 \mathrm{~mm}$ long and $3 \mathrm{~mm}$ wide, that intersected at the midpoints. The circle had an outside diameter of $16 \mathrm{~mm}$ and an inside diameter of $13 \mathrm{~mm}$. A shielded 28-V dc bulb (GE 1218), centered in the ceiling, served as the houselight.

Two solenoid-operated grain feeders were backmounted to the stimulus panel in such a way that each feeder could be independently raised to the same hopper opening. Only one of the hoppers, which contained mixed grain (Purina Pigeon Grain), was used in the present study.

BRS solid-state equipment located in an adjoining room controlled the presentation of stimulus events and recorded responses. Sound masking was provided by white noise and a blower fan.

\section{Procedure}

The birds were initially trained to eat from the food hopper, and were then autoshaped to red and green stimuli. Eight-second conditioned stimulus (CS) presentations were followed by $3 \mathrm{sec}$ access to mixed grain. Responses to an illuminated key during the 8-sec CS interval terminated the CS and were immediately reinforced. Trials were separated by a 30-sec intertrial interval (ITI). Each stimulus (red or green) was presented five times on each of the three response keys, in a random order, during each 30-trial session of autoshaping. Once responding was established (two to three sessions), the ITI was reduced to $5 \mathrm{sec}$, the reinforcement duration was rectuced to $2.5 \mathrm{sec}$, and a single response was required to produce reinforcement. Over the next five sessions of single stimulus training, the response requirement was increased to a fixed ratio (FR) of 10 responses. The houselight remained on throughout each session of pretraining.

On the day following the last pretraining session, the birds began training on a red and green match/mismatch task. Each trial was initiated by illuminating the center response key with either a red or a green sample stimulus. Ten pecks to the sample were required to illuminate comparison stimuli, which were presented on the side keys. A single peck to the correct comparison (defined below) was reinforced with $2.5 \mathrm{sec}$ access to grain, and it initiated a 5-sec ITI. A response to the incorrect comparison was followed only by the ITI.

Red and green were presented equally often as samples and comparisons, and equal numbers of matching and mismatching trials (48 of each) were scheduled within each 96-trial session. Trials were 
randomized with the following constraints: The same stimulus could not appear as the sample on more than three consecutive trials; the correct comparison stimulus could not appear in the same location (left or right) on more than three consecutive trials; and the same kind of response (matching or mismatching) was not scheduled as the correct response on more than three consecutive trials.

The birds were randomly assigned to the four conditions shown in Figure 1. For one group of birds, Group Houselight-Match/ Dark ITI (HM/Dark), a matching response was reinforced when the houselight was on during a trial, whereas a mismatching response was reinforced when the houselight remained off during a trial. The contingencies between houselight illumination level and correct response requirement were reversed for a second group of birds, Group Houselight-Odd/Dark ITI (HO/Dark).

Groups HM/Dark and HO/Dark represented the conditions used in the earlier study. For both groups, a change in houselightproduced illumination was associated with houselight-cued trials, whereas no change in houselight illumination was associated with dark-cued trials. To control for changes per se, two additional groups were included. One of these groups, Group HouselightMatch/Bright ITI (HM/Bright), was required to match samples and comparisons when the houselight was on and to mismatch when the houselight was off. However, the houselight remained on during all ITIs, so that changes in houselight-produced illumination were associated with dark-cued trials but not with houselight-cued trials. For the fourth group, Group Houselight-Odd/Bright ITI (HO/Bright), mismatching was correct when the houselight was on during a trial, whereas matching was correct when the houselight was off during a trial. For group HO/Bright, changes in illumination were associated only with the dark-cued component of the task.

Although Groups HM/Bright and HO/Bright were included primarily to control for houselight change, the contingencies established for these two groups introduced houselight illumination during the ITI as an additional factor. Thus, the design of the experiment allowed us to assess three possible effects that could be attributed to houselight manipulations. These included the effects of illumination during a trial (i.e., the effects of using houselighton vs. houselight-off instructions); the effects of associating houselight changes with only one of the two task components (either with the houselight-cued component for Groups HM/Dark and HO/Dark, or with the dark-cued component for Groups HM/Bright and HO/Bright); and the effects of illumination during the ITI.

The birds received a total of 32 daily sessions of training on the color (red and green) match/mismatch task. Following this training, the binds were reassigned so that 1 bind in each group was main- tained in that group, and the other 3 birds in the group were uniquely assigned to the other three groups. Following this reassignment, the birds were trained on a shape (plus and circle) match/mismatch task, using the same procedure as that used during color training. Training on the shape task continued for a total of 72 sessions.

\section{RESULTS}

\section{Color Training}

Acquisition of the color match/mismatch task is presented in Figure 2. Each data point represents performance on one of the task components, averaged across birds within a condition and averaged over blocks of four sessions.

One effect that was obtained at the outset of training was that birds in all groups showed an initial oddity bias. Performance on the mismatch (oddity) component of the task, averaged over the four groups, was $61.5 \%$ correct on Session Block 1. Performance on the matching component was slightly below chance, averaging $47.6 \%$ correct. A single-factor repeated measures analysis of variance performed on the data from Block 1 revealed that the difference between mismatching performance and matching performance was significant $[F(1,15)=34.51$, $p<.001]$.

A bias to respond to the nonmatching comparison stimulus in matching-to-sample and oddity-from-sample tasks has been reported elsewhere (e.g., Carter \& Werner, 1978; Cumming \& Berryman, 1965; Zentall \& Hogan, 1978). The bias has been attributed to the fact that sample responses go unrewarded, so that birds avoid pecking that same (matching) stimulus when it appears as a comparison stimulus. Thus, there is nothing remarkable about our obtaining this effect in the present experiment. However, the oddity bias does indicate that birds in all groups had no difficulty discriminating red from green at the outset of training, and that this discrimination was not affected by the level of chamber illumination during the trial or by the level of illumination during the ITI.

\section{HOUSELIGHT - TASK COMPONENT CONTINGENCY}

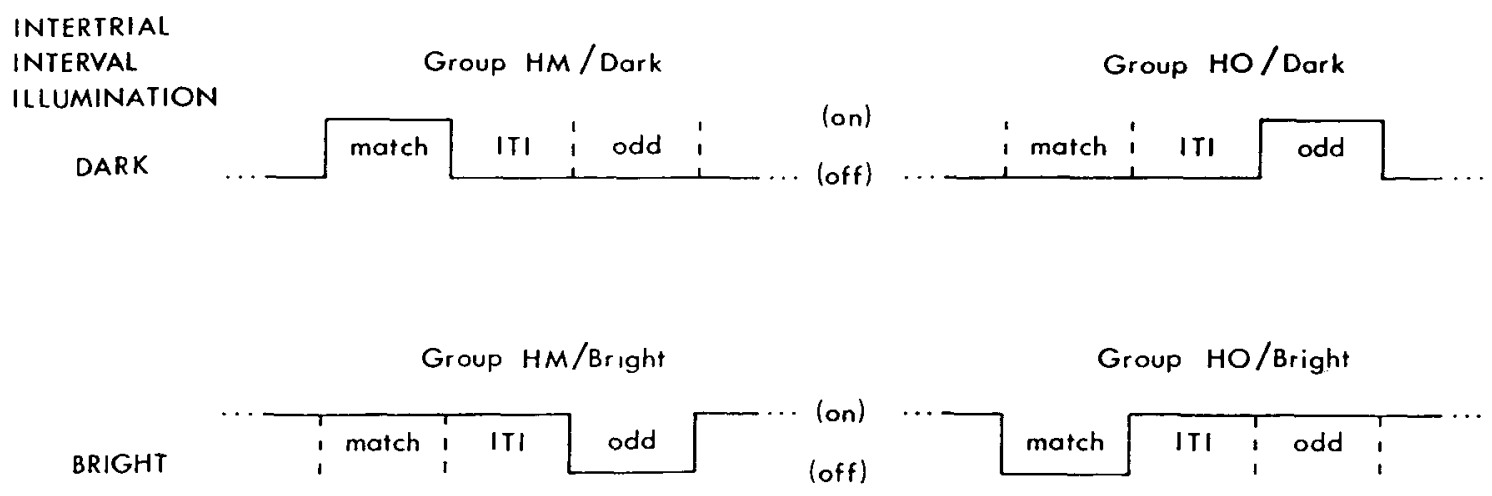

Figure 1. General design used in the present experiment. The figure illustrates the level of chamber illumination used to signal each component of the task (match or odd) and the points at which changes in the houselight occurred across trials (on either houselight-cued or dark-cued trials) for each of the four groups. Parenthetical entries in the center of the figure indicate houselight illumination levels (on or ofi). See text for additional details. 


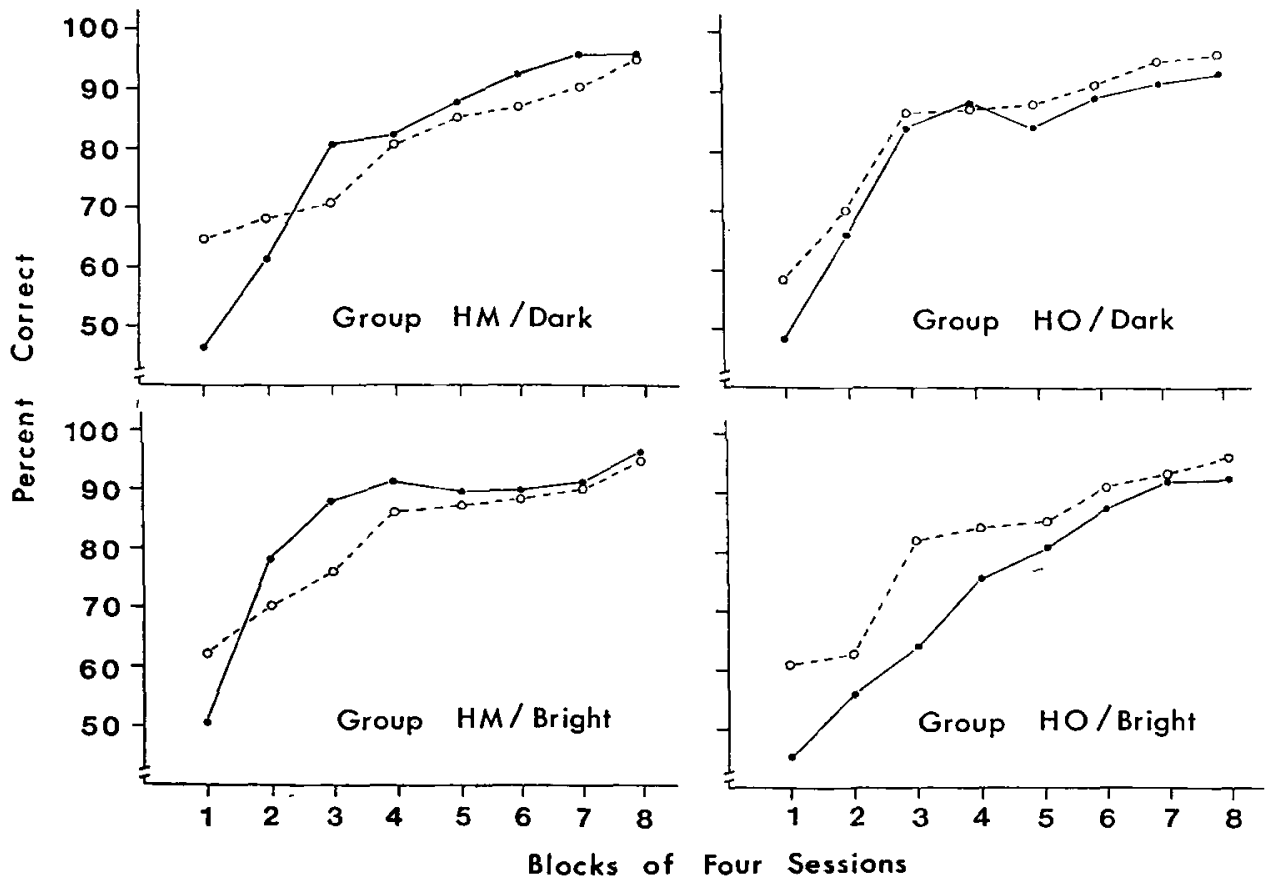

Figure 2. Acquisition of the color match/mismatch task in the first half of the experiment. Performance on each component of the task is shown separately for each of the four groups. Matching performance is represented by the solid lines, mismatching by the dashed lines.

There was some evidence in each of the groups that after Session Block 1, performance on the houselight-cued component of the task was facilitated relative to performance on the dark-cued component of the task. However, better performance on houselight-cued trials did not appear to depend on houselight change per se. For example, the curves for Groups HM/Dark and HM/Bright in Figure 2 (upper left and lower left panels, respectively) show that matching performance (solid lines) was generally above mismatching performance (dashed lines) for both groups, although houselight changes were associated with the houselight-cued (matching) task component in only one of these groups (Group HM/Dark). Better performance on houselight-cued trials was also observed for Groups HO/Dark and HO/Bright. As shown in the upper right and lower right panels of Figure 2, houselight-cued mismatching (dashed lines) was consistently above darkcued matching (solid lines) for these two groups. Once again, however, houselight changes were associated with the houselight-cued (mismatching) component for only one of these groups (Group HO/Dark). We should also note that better performance on houselight-cued mismatching trials for Groups HO/Dark and HO/Bright could be attributed either to the positive effects of illuminating the houselight during a trial or to the initial oddity bias.

To test for the possible effects of the houselight manipulations early in training, the data obtained during the first half of the experiment (Session Blocks 1-4) were analyzed separately from the data obtained during the second half of the experiment (Session Blocks 5-8). The data were analyzed using a four-way mixed design analysis of variance, one that included two between-groups factors and two repeated factors. One between-groups factor was the houselight level and task component contingency (houselight-match vs. houselight-odd). We will refer to this factor as the houselight contingency factor. ITI illumination (dark vs. bright) was treated as the second between-groups factor. Task component within each group (match or odd) and session blocks (1-4) were the two repeated factors. In this analysis, any differential effect of houselight-on versus houselight-off during a trial would be revealed by a significant two-way interaction between houselight contingency and task component. On the other hand, if a change in illumination, and not the absolute level of illumination, contributed to differences in performance on the matching and mismatching components of the task, this would be revealed by a significant three-way interaction between houselight contingency, ITI, and task component.

The analysis revealed that there was no overall difference in performance between the HM and HO conditions, and there was no effect of ITI (both $F \mathrm{~s}<1$ ). Performance improved with session blocks $[F(3,36)=84.12$, $p<.001$, but within groups, the difference in performance on the matching component and on the mismatching component just failed to reach significance [matching, mean $=69.0 \%$; mismatching, mean $=73.2 \%$; $F(1,12)=4.41, p>.05]$. Neither of the interactions that were of interest was significant [houselight contingency $\times$ task component, $F(1,12)=3.72, p>.05$; houselight 
contingency $\times$ ITI $\times$ task component, $F(1,12)=3.84$, $p>.05]$. Thus, the analysis indicated that houselight levels during a trial, houselight changes per se, and ITI illumination had no significant effects over the first four session blocks.

However, a significant task component $\times$ session blocks interaction was obtained $[F(3,36)=10.42$, $p<.001]$, and the houselight contingency $\times$ task component $X$ session blocks interaction was also significant $[F(3,36)=5.78, p<.01]$. The initial oddity bias discussed previously was one factor that contributed to these interactions. A second source of interaction can be seen in Figure 2. For the HM condition, mismatching performance was initially above matching performance, due to the initial oddity bias, but by Session Block 3, matching performance exceeded mismatching performance. This was true for both Group HM/Dark and Group HM/Bright. In contrast, no similar crossover effect was observed for the HO condition.

The sources of interaction obtained in the overall analysis were localized statistically by first examining the effects of the repeated factors within each houselight contingency condition and then, where indicated, testing for differences between matching and mismatching performance for each session block. For the HM condition, there was no difference between Groups HM/Dark and $\mathrm{HM} /$ Bright $[F(1,6)=1.03]$, and no difference (overall) on the matching and mismatching components of the task $[F(1,6)<1]$. However, task component and session blocks interacted $[F(3,18)=12.13, p<.001]$. On Session Block 1 , mismatching performance $(63.5 \%)$ was significantly above matching performance $(48.5 \%)[F(1,6)$ $=12.53, p<.05]$. This difference disappeared by Session Block 2 (mismatching, mean $=69.5 \%$; matching, mean $=69.5 \% ; F<1$ ). By Session Block 3, mismatching performance $(74.13 \%)$ was below matching performance $(84.38 \%)$, and the difference was significant $[F(1,6)=6.14, p<.05]$.

A similar analysis conducted on the data for the HO condition revealed only that mismatching was significantly above matching $[F(1,6)=8.40, p<.05]$ over the four session blocks. The two groups within the HO condition (HO/Dark and HO/Bright) did not differ and there were no significant interactions.

The first four session blocks were characterized by rapid, but nonetheless systematic, changes in performance on the two components of the task. On Session Block 1, birds in all groups showed an oddity bias, one that was not differentially affected by houselight levels during the trial or ITI or by houselight changes. On the other hand, on Session Blocks 2 and 3, it appeared that performance on the houselight-cued task component was facilitated relative to performance on the dark-cued component. The clearest evidence for this houselight effect was the crossover in performance on the match and mismatch components of the task for the HM condition.

The effects of the houselight manipulations during the second half of the color training phase (Session Blocks 5-8) were analyzed in a separate four-way anal- ysis of variance. The only significant effects obtained were the session blocks effect $[F(3,36)=12.64, p<.001]$ and the houselight contingency $\times$ task component interaction $[F(1,12)=5.71, p<.05]$ (all other $F$ s $<1)$. The source of this interaction is illustrated in Figure 2. For all groups, houselight-cued performance exceeded darkcued performance (i.e., matching was higher than mismatching in the HM groups, whereas mismatching was higher than matching in the HO groups). However, this difference was quite small, averaging $3.1 \%$ between the two task components, and no statistically reliable difference was obtained when the data for each of the houselight contingency conditions were considered separately.

\section{Shape Training}

One of the birds (Bird 7) in Group HM/Bright failed to show any evidence of learning the shape match/mismatch task at any point in training. Data for Bird 7 were not included in the analyses and are not otherwise presented.

Acquisition of the shape match/mismatch task for each of the four groups is presented in Figure 3. Each data point represents performance on one component of the task, averaged over birds within a condition and averaged over blocks of eight sessions.

Improvements in performance began to appear during Session Block 2, and as the curves in Figure 3 illustrate, noticeable improvements in performance occurred on the houselight-cued component of the task before any evidence of learning was obtained on the dark-cued component of the task. As shown in Figure 3, for Groups HM/Dark and HM/Bright (left-hand panels), houselightcued matching performance (solid lines) exceeded darkcued mismatching performance (dashed lines). Similarly, for Groups HO/Dark and HO/Bright (right-hand panels) houselight-cued mismatching performance (dashed lines) exceeded dark-cued matching performance (solid lines). Better performance on houselight-cued trials did not appear to depend on whether houselight changes vere associated with the houselight-cued or dark-cued component of the task. In either case, performance on the houselight-cued task component exceeded performance on the dark-cued task component.

In addition to the houselight effect, the overall level of performance appeared to be facilitated for the two groups that were exposed to houselight illumination during the ITI (Groups HM/Bright and HO/Bright). The effect of ITI illumination shows up most clearly on the dark-cued component of the match/mismatch task (e.g., compare HM/Dark mismatching with HM/Bright mismatching), and the effect is also apparent when one compares houselight-cued mismatching performance for Groups HO/Dark and HO/Bright.

For the purpose of analyzing the data, scores for individual birds were averaged over blocks of 24 sessions. The effects shown in Figure 3 were preserved when data were thus combined. Table 1 shows the performance of individual birds for each of the three blocks of 24 ses- 

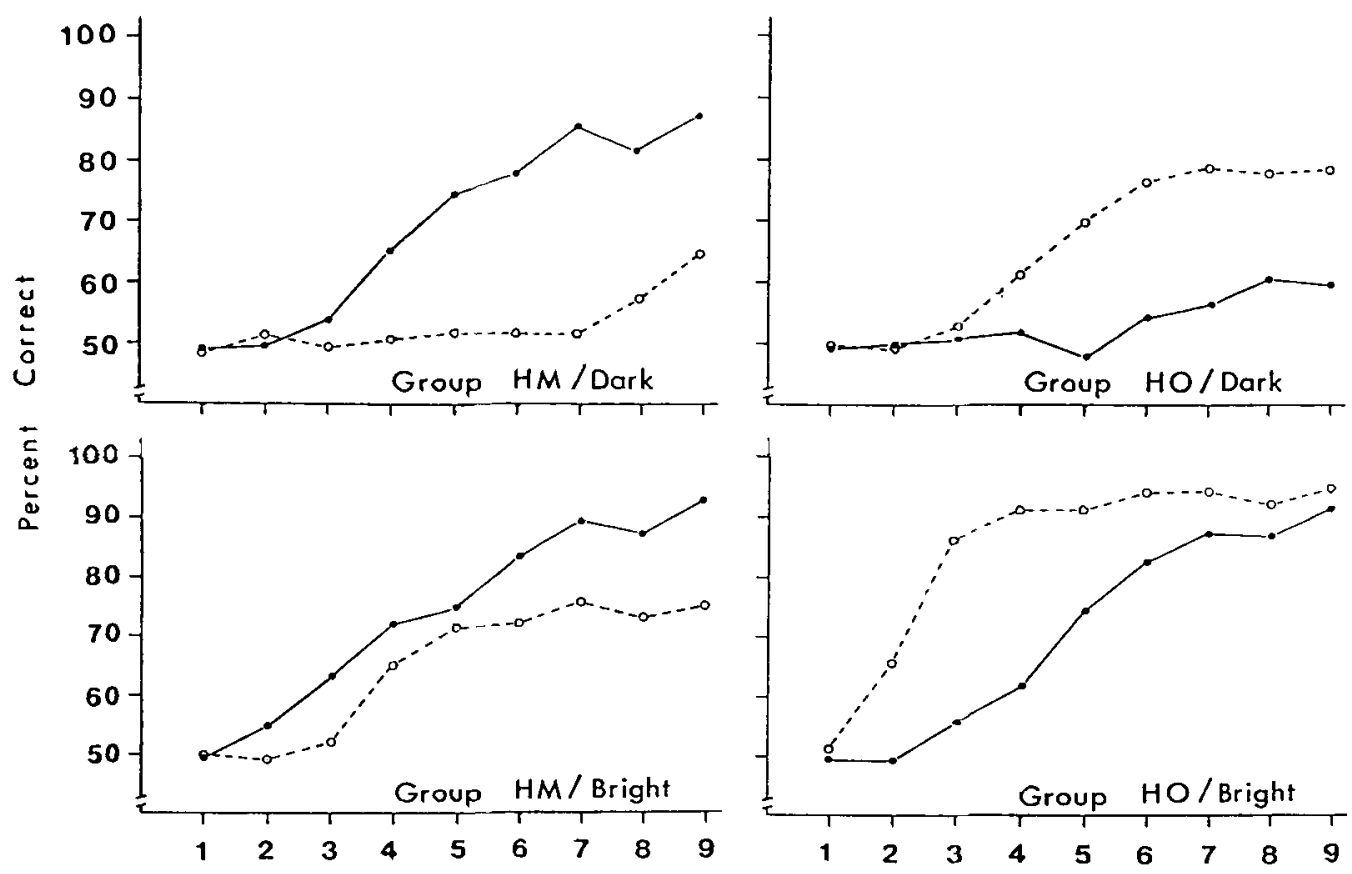

Blocks of Eight Sessions

Figure 3. Acquisition of the shape match/mismatch task in the second half of the experiment. Performance on each component of the task is shown separately for each of the four groups. Matching performance is represented by the solid lines, mismatching by the dashed lines.

sions. Performance was quite variable within each group. Poor performance on both of the task components by 1 bird in each group contributed to some of the variability (Birds 5, 1, and 10 in Groups HM/Dark, HO/Dark, and HM/Bright, respectively). On the other hand, Bird 20 in Group HO/Bright showed an unusually high level of performance on the dark-cued component of the task. The variability in performance did not appear to be systematically related to any prior experience (during color training) with a specific houselight-level/task-component contingency. Bird 9, for example, was assigned to Group $\mathrm{HO} / \mathrm{Bright}$ during both phases of the experiment, whereas Bird 20 was assigned to Group HM/Bright during color training and to Group HO/Bright during shape training. A comparison of performance for these two birds, and similar comparisons for other birds, failed to reveal any difference that could be attributed to the birds' prior experience.

The data for Group HO/Bright were atypical in another respect. All birds in Group HO/Bright showed evidence of learning the houselight-cued (mismatching) component of the task within the first 24 sessions of training, whereas performance on the houselight-cued task component remained close to chance for birds in the other three conditions (see Table 1).

The data shown in Table 1 were subjected to a fourway mixed-design analysis of variance, for unequal sample sizes. The factors in the analysis were the same as those used in the analysis of the color data. Once again, we were interested primarily in the interaction between houselight contingency and task component, as this would reveal the houselight effect. The effect of houselight changes would be revealed by a significant houselight contingency $\times$ ITI $\times$ task component interaction.

The analysis revealed no difference, overall, between the $H M$ and $H O$ conditions $[F(1,11)=1.16, p>.05]$, but a large main effect of ITI illumination $[F(1,11)=$ $11.60, p<.01]$. Thus, performance for groups trained with bright ITIs was significantly above performance for groups trained with dark ITIs. This was a curious finding, as no comparable effect was obtained with color stimuli.

There was no main effect of task component $(F<1)$, but the houselight contingency $\times$ task component interaction was significant $[F(1,11)=27.28, p<.001]$. As shown in Figure 3, houselight-cued performance exceeded dark-cued performance in all groups. The three-way interaction of interest (houselight contingency $\times$ ITI $\times$ task component) was not significant $(F<1)$ indicating that houselight changes did not contribute to the overall difference between houselight-cued and dark-cued performance.

Additional significant interactions obtained in the overall analysis were those that involved session blocks as one of the factors. The interaction between ITI and session blocks was significant $[F(2,22)=3.51, p<.05]$. This interaction was due to the increased difference (over session blocks) in performance for the bright ITI condition relative to the dark ITI condition.

The houselight contingency $\times$ task component $\times$ session blocks interaction was significant $[F(2,22)=5.78$, 
Table 1

Performance for Individual Birds on Each Task Component During Shape Training

\begin{tabular}{|c|c|c|c|c|c|c|}
\hline & \multicolumn{3}{|c|}{ Match Component } & \multicolumn{3}{|c|}{ Mismatch Component } \\
\hline & Block 1 & Block 2 & Block 3 & Block 1 & Block 2 & Block 3 \\
\hline & \multicolumn{6}{|c|}{ Houselight-Match Condition } \\
\hline & \multicolumn{3}{|c|}{ Houselight On } & \multicolumn{3}{|c|}{ Houselight Off } \\
\hline $\begin{array}{l}\text { HM/Dark } \\
\text { Bind } 15 \\
\text { Bird } 2 \\
\text { Bird } 5 \\
\text { Bind } 17\end{array}$ & $\begin{array}{l}51.8 \\
55.2 \\
47.5 \\
49.9\end{array}$ & $\begin{array}{l}91.4 \\
75.1 \\
50.2 \\
75.8\end{array}$ & $\begin{array}{l}97.8 \\
86.6 \\
69.5 \\
83.7\end{array}$ & $\begin{array}{l}50.0 \\
51.9 \\
49.8 \\
49.4\end{array}$ & $\begin{array}{l}50.0 \\
52.3 \\
53.3 \\
50.3\end{array}$ & $\begin{array}{l}66.5 \\
51.1 \\
56.7 \\
58.7\end{array}$ \\
\hline Mean & 51.1 & 73.1 & 84.4 & 50.3 & 51.5 & 58.3 \\
\hline \multicolumn{7}{|l|}{ HM/Bright } \\
\hline $\begin{array}{lr}\text { Bird } 6 \\
\text { Bird } 4 \\
\text { Bird } 10\end{array}$ & $\begin{array}{l}53.0 \\
64.6 \\
49.8\end{array}$ & $\begin{array}{l}82.6 \\
88.0 \\
58.1\end{array}$ & $\begin{array}{l}91.7 \\
95.3 \\
80.0\end{array}$ & $\begin{array}{l}53.2 \\
47.9 \\
50.1\end{array}$ & $\begin{array}{l}79.5 \\
77.6 \\
50.6\end{array}$ & $\begin{array}{l}76.7 \\
93.7 \\
51.4\end{array}$ \\
\hline \multirow[t]{3}{*}{ Mean } & 55.8 & 76.2 & 89.0 & 50.4 & 69.2 & 73.9 \\
\hline & \multicolumn{6}{|c|}{ Houselight-Odd Condition } \\
\hline & \multicolumn{3}{|c|}{ Houselight Off } & \multicolumn{3}{|c|}{ Houselight On } \\
\hline HO/Dark & & & & & & \\
\hline $\begin{array}{l}\text { Bird } 18 \\
\text { Bird } 1 \\
\text { Bird } 14 \\
\text { Bird } 11\end{array}$ & $\begin{array}{l}49.7 \\
51.6 \\
50.3 \\
50.6\end{array}$ & $\begin{array}{l}48.8 \\
64.3 \\
59.2 \\
48.4\end{array}$ & $\begin{array}{l}53.0 \\
56.9 \\
81.3 \\
50.1\end{array}$ & $\begin{array}{l}52.0 \\
48.4 \\
55.2 \\
49.1\end{array}$ & $\begin{array}{l}71.5 \\
54.1 \\
79.0 \\
76.3\end{array}$ & $\begin{array}{l}84.5 \\
61.0 \\
93.8 \\
78.8\end{array}$ \\
\hline Mean & 50.6 & 55.2 & 60.3 & 51.2 & 70.2 & 79.5 \\
\hline HO/Bright & & & & & & \\
\hline $\begin{array}{l}\text { Bird } 9 \\
\text { Bird } 3 \\
\text { Bird 19 } \\
\text { Bird } 20\end{array}$ & $\begin{array}{l}48.4 \\
47.9 \\
49.3 \\
62.2\end{array}$ & $\begin{array}{l}65.7 \\
66.2 \\
65.1 \\
93.8\end{array}$ & $\begin{array}{l}90.0 \\
84.4 \\
84.5 \\
94.3\end{array}$ & $\begin{array}{l}61.9 \\
75.5 \\
70.3 \\
63.5\end{array}$ & $\begin{array}{l}87.2 \\
81.1 \\
94.5 \\
87.7\end{array}$ & $\begin{array}{l}91.7 \\
96.2 \\
93.4 \\
92.5\end{array}$ \\
\hline Mean & 52.0 & 72.7 & 88.3 & 67.8 & 87.6 & 93.5 \\
\hline
\end{tabular}

$p<.01]$, as was the houselight contingency $\times$ ITI $\times$ task component $\times$ session blocks interaction $[F(2,22)=$ $6.48, p<.01]$. The sources of these two interactions can be seen in Figure 3 and in the data presented in Table 1. For the two groups trained with dark ITIs, houselight contingency produced no differential effect; that is, houselight-cued performance was comparable for Groups HM/Dark and HO/Dark, as was dark-cued performance. However, houselight contingency did appear to make some difference under the bright ITI conditions. As mentioned earlier, houselight-cued (mismatching) performance for Group HO/Bright was well above chance (67\%) on the first session block, whereas houselight-cued (matching) performance for Group HM/Bright averaged $55.8 \%$ on Session Block 1. In addition, by Session Block 3, the difference between houselight-cued and darkcued performance for individual birds in Group HO/Bright was quite small, averaging $5.2 \%$, whereas greater variability in individual performance on the houselight-cued and dark-cued task components was observed for birds in Group HM/Bright. However, these differences between Groups HO/Bright and HM/Bright, which would appear to indicate a houselight contingency effect under the bright ITI condition, should be considered with some caution, given the degree of variability in individual performance in Group HM/Bright.

\section{DISCUSSION}

The effects of the houselight manipulations obtained in the present experiment can be summarized as follows. When trained on the color match/mismatch task, birds in all groups showed an initial oddity bias, one that was independent of the level of illumination during the trial and the ITI. Acquisition of the two components of the color task was rapid in all groups. Although there was some evidence that houselight-cued performance was facilitated, the differences in performance on the houselight-cued and dark-cued components of the color task were small, and the differences that were obtained did not depend on houselight changes per se. Finally, illumination during the ITI did not affect performance. Thus, when trained with color stimuli, the birds readily discriminated red from green and appeared to use the houselight as a higher order cue for directing choice behavior.

When the birds were subsequently trained on the shape match/mismatch task, large differences between houselight-cued and dark-cued performance were obtained, with better performance on the houselight-cued component of the task. The data obtained for Groups HM/Dark and HO/Dark are quite similar to those reported earlier, in terms of the pattern of acquisition and in terms of absolute levels of performance (see Edwards et al., 1985, Figure 1, Blocks 1-11). The results obtained for groups HM/Bright and HO/Bright extend the previous findings and rule out the possibility that the asymmetry in rates of learning the components of the shape task could be attributed to houselight changes, to differential reinforcement, or to the order in which the problems were trained.

The novel finding in the present experiment was that illumination during the ITI facilitated acquisition of the shape task, but not of the color task. Figure 4, which summarizes the main findings of the experiment, illustrates the effect of ITI illumination on the shape task and the absence of any comparable effect on the color task. As shown in the figure, the best performance on the shape task was obtained when both the trial and the ITI were illuminated. Intermediate levels of performance were obtained when the houselight was on either during a trial or during the ITI. The poorest level of performance was observed when the houselight was off during both the trial and the ITI. Indeed, 6 of the 8 birds trained under the dark ITI condition showed little evidence of learning the dark-cued task, even after 72 sessions of training. The effect of ITI illumination is perhaps the most puzzling result obtained in the present experiment. Why would illumination during the ITI facilitate discriminations between stimuli presented during the trial, and why would this effect be confined to the shape task?

We have considered several explanations for these results. We will not give all of these a thorough treatment here because the explanations are necessarily post hoc and 


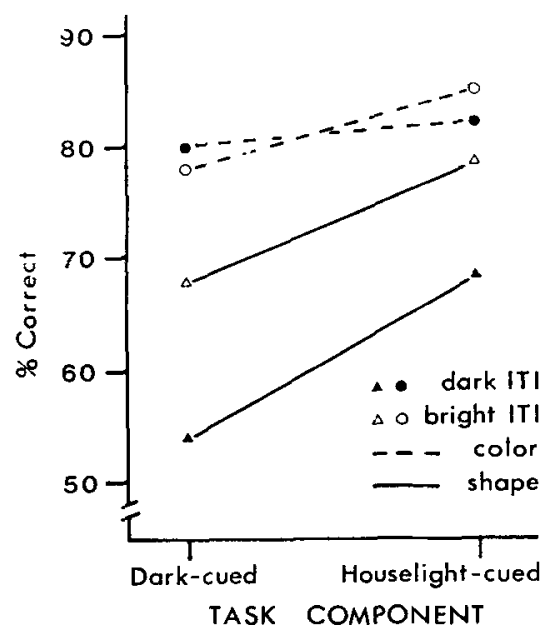

Figure 4. Overall performance on the color match/mismatch task (dashed lines) and on the shape match/mismatch task (solid lines) as a function of the level of illumination during the trial and during the intertrial interval.

all are problematic. However, we will summarize some of the more interesting possibilities.

The first explanation we considered was based on the notion of divided or shared attention (e.g., Maki \& Leith, 1973). We reasoned that different levels of chamber illumination (across trials) had the effect of creating discriminable differences in the keylight stimuli along a brightness dimension. When samples were presented in an otherwise darkened chamber, keylight brightness produced by the onset of the sample stimulus may have been highly salient, and control of responding by brightness per se may have competed with control by other discriminable differences between the sample and comparison stimuli. On the other hand, when samples were presented in an illuminated chamber, the salience of keylight brightness cues may have been reduced or washed out. Changes in the salience of the keylight stimuli along a brightness dimension would explain why performance was poorer on dark-cued trials than on houselight-cued trials. If the birds attended to keylight brightness on darkcued trials, then performance would suffer on those trials, because brightness would not provide any differential cue for choice responding.

This explanation provides a reasonable account of the shape data. The notion of differential control by keylight brightness cues can also be extended to account for the effects of ITI illumination. Presumably, the salience of keylight onset would differ both as a function of the level of chamber illumination during a trial and as a function of the illumination level just prior to the start of a trial (i.e., during the ITI). Thus, keylight onset would be highly salient when the houselight was off during the ITI and during the subsequent trial. The salience of keylight onset would be reduced, however, when the level of chamber illumination changed from dark to bright, or from bright to dark, at the start of a trial (i.e., salience would be reduced when changes in houselight illumination levels coincided with sample onset). Finally, keylight onset would be least salient when the houselight remained on throughout the ITI and the subsequent trial.

One assumption inherent in this analysis is that birds can, in some sense, "decompose" (e.g., Riley, 1984) a shape stimulus. In other words, a bird may process a shape stimulus in terms of a brightness component and a form component, and attend to just one of these components while ignoring the other. The role of the houselight would be to change the relative salience of the brightness component, and thereby produce shifts in attention between brightness and form cues. However, to account for the absence of any houselight effect on the color problem, one would have to make the additional claim that colors cannot be decomposed into brightness and hue components. This second claim does have some intuitive appeal. A red sample may be perceived as such across different levels of background illumination (i.e., birds may show color constancy), and it is unlikely that a bird could escape noticing the color of a key, whether it attended to the entire key or to some circumscribed portion of the key. The fact that the birds in the present experiment showed an initial oddity bias under all illumination conditions is consistent with this argument.

One problem with this attentional account is that although each of the necessary assumptions may be plausible, there is no independent evidence that keylight brightness might compete for control over responding in a dark (vs. bright) chamber, nor is there evidence that birds process form and color stimuli in the ways we have just described. A second, more general problem is that the notion of attention could also be used to explain the opposite pattern of results. Suppose, for example, that the birds had shown better performance on the dark-cued task component than on the houselight-cued task component. One could argue that the houselight had the effect of highlighting chamber cues that might have distracted the birds from the keylight stimuli and thereby disrupted performance on the houselight-cued (not the dark-cued) task component. For these reasons, this attentional explanation for the houselight effect remains speculative.

The second explanation we considered likewise emphasized the role of keylight brightness cues and changes in the salience of these cues across different levels of houselight illumination. However, the second explanation sought to account for the results on the basis of possible differences in the response-eliciting properties of shape and color stimuli. We reasoned that brightness, color, and form dimensions are not just orthogonal to each other. Brightness may differ from the other two dimensions in that a change within a brightness dimension may engage different response systems, whereas a change within a color or form dimension is not likely to produce a difference in the nature of the response. Birds may emit a response when presented with what is perceived as a dim keylight, whereas a bright keylight may tend to elicit responses. However, it is unlikely that the type of response 
would shift with a change from, say, a red stimulus to a green stimulus of equal brightness.

In the context of the match/mismatch task, it seems possible that keylight onset in a dark chamber tended to elicit responses, but that birds emitted pecks in a bright chamber. However, apart from the problem of how to distinguish between these two types of responses, two assumptions would have to be made in order to account for the overall pattern of results. The first is that elicited responses are not well controlled by differences in exteroceptive stimuli. The second assumption is that shape stimuli tend to elicit responses, and are more likely to do so in a dark chamber than in a bright chamber, whereas colors would not elicit responses under any of the houselight illumination conditions. Both of these assumptions are suspect.

The third possible explanation is based on the notion of intertrial interference, and a possible release from intertrial interference effects produced by a stimulus (i.e., the houselight) interpolated between trials. Studies have shown that one source of error in matching-to-sample tasks is birds' tendency to choose the same stimulus on trial $n$ as that chosen on trial $n-1$ (Roberts, 1980; Roitblat \& Scopatz, 1983). Any manipulations that might disrupt memory for the previous trial would reduce intertrial interference and thereby improve performance.

Something analogous to intertrial interference might have been present in the current experiment, but in this case, it would have taken the form of interference between the two task components. For example, if a houselightcued matching trial preceded a dark-cued mismatching trial, then memory for having made a matching response might have disrupted performance on the subsequent mismatching trial. One could account for the shape data by assuming that the effect of illumination during the ITI (and/or during a trial) was to disrupt memory for the response on the preceding trial (or, more generally, to disrupt memory for the other task component), and thus to remove this potential source of interference.

How plausible is this explanation? One problem, of course, is that memory for the previous trial would not interfere with performance if the response required on trial $n-1$ was the same as that required on trial $n$. That is, although some interference might be expected, it is not clear that intertask interference due to memory for previous responses (or memory for the other task component) would preclude learning on the dark-cued task component. In addition, it is not clear how an intertask interference account can be reconciled with the color data, unless one argues that the ease of learning color associations under the two houselight conditions may have masked any potential interference effects.

None of the possible explanations discussed here is satisfactory, and we should perhaps acknowledge that an interpretation of the data in terms of any current theory is problematic. We should also acknowledge that there may be a simpler (but not obvious) explanation for the present results that would allow us to account for the houselight effects obtained without reference to a cognitive theory of conditional discrimination performance. In any event, our summary of the findings is necessarily descriptive: The birds had no difficulty in discriminating samples and comparisons when the match/mismatch task was trained with color stimuli, but samples and comparisons were not readily discriminated when shapes were used to train the task. Ilumination during the ITI, however, appeared to facilitate the discriminations required on the shape match/mismatch task.

An adequate account of these findings will require additional research. Nonetheless, the present experiment makes a contribution by providing several control conditions against which the earlier matching/mismatching transfer data may be evaluated (see Edwards et al., 1985). The present results also suggest that the relative difficulty of a discrimination between form stimuli is not fixed in any absolute sense, but may depend instead on the context in which forms are presented.

\section{REFERENCES}

Born, D. B., \& Peterson, J. L. (1969). Stimulus control acquired by the components of two color-form compound stimuli. Journal of the Experimental Analysis of Behavior, 12, 437-442.

Carter, D. E., ECKerman, D. A. (1975). Symbolic matching by pigeons: Rate of learning complex discriminations predicted from simple discriminations. Science, 187, 662-664.

Carter, D. E., \& WERnER, T. J. (1978). Complex learning and information processing by pigeons: A critical analysis. Joumal of the Experimental Analysis of Behavior, 29, 565-601.

Cook, R. G. (1980). Retroactive interference in pigeon short-term memory by a reduction in ambient illumination. Joumal of Experimental Psychology: Animal Behavior Processes, 6, 326-338.

Cumming, W. W., Berryman, R. (1965). The complex discriminated operant: Studies of matching-to-sample and related problems. In D. I. Mostofsky (Ed.), Stimulus generalization. Stanford, CA: Stanford University Press.

Edwards, C. A., Miller, J. S., Zentall, T. R. (1985). Control of pigeons' matching and mismatching performance by instructional cues. Animal Learning \& Behavior, 13, 383-391.

FARTHING, G. W., OPUDA, M. J. (1974). Transfer of matching-tosample in pigeons. Journal of the Experimental Analysis of Behavior, 21, 199-213.

Fartimng, G. W., Wagner, J., Gilmour, S., \& Waxman, H. (1977). Short-term memory and information processing in pigeons. Learning \& Motivation, 8, 520-532.

MAKI, W., LeIrT, C. (1973). Shared attention in pigeons. Journal of the Experimental Analysis of Behavior, 19, 345-349.

RuLEY, D. A. (1984). Do pigeons decompose stimulus compounds? In H. L. Roitblat, T. G. Bever, \& H. S. Terrace (Eds.), Animal cognition. Hillsdale, NJ: Erlbaum.

RoserTs, W. A. (1980). Distribution of trials and intertrial repetition in delayed matching to sample with pigeons. Joumal of Experimental Psychology: Animal Behavior Processes, 6, 217-237.

Roberts, W. A., GraNt, D. S. (1978). An analysis of light-induced retroactive inhibition in pigeon short-term memory. Journal of Experimental Psychology: Animal Behavior Processes, 4, 219-236.

Romblat, H. L., e ScopaTZ, R. A. (1983). Sequential effects in pigeon delayed matching to sample performance. Jourmal of Experimental Psychology: Animal Behavior Processes, 9, 202-221.

Seraganian, P. (1979). Extradimensional transfer in the easy-to-hard effect. Learning \& Motivarion, 10, 39-57.

Tranberg, D., Rillng, M. (1980). Delay-interval illumination changes interfere with pigeon short-term memory. Joumal of the $E x$ perimental Analysis of Behavior, 33, 39-49.

ZENTALL, T. R., \& HogaN, D. E. (1978). Same/different concept learn- 
ing in the pigeon: The effect of negative instances and prior adaptation to the transfer stimuli. Journal of the Experimental Analysis of Behavior, 30, 177-186.

\section{NOTE}

1. The houselight effect obtained in Edwards et al.'s (1985) study may appear to be at odds with the results of other experiments that have included houselight manipulations. Specifically, studies of delayed matching-to-sample have shown that houselight presentations during the delay interval disrupt performance (e.g., Roberts \& Grant, 1978; see also Cook, 1980; Tranberg \& Rilling, 1980). However, the apparent disparity between the positive effect of houselight illumination on the shape match/mismatch task and the negative effect of houselight inter- polated during a delay interval in a delayed matching-to-sample task is probably due to three factors. First, in the match/mismatch task, the sample remained on when choice stimuli were presented (i.e., the task involved simultaneous matching or mismatching). Second, the effect of houselight illumination on the match/mismatch task was assessed during acquisition, whereas the effect of illumination interpolated during a delay is generally assessed following acquisition. Third, in the match/mismatch task, the houselight was used as a higher order conditional cue, whereas in Roberts and Grant's study, the houselight was not conditionally related to the task.

(Manuscript received May 12, 1986;

revision accepted for publication November 25, 1986.) 